\title{
SECOND CROP GROWING DURING THE DRY SEASON IN LOWER BURMA ${ }^{1}$ )
}

\author{
C. T. DE WIT \\ Formerly: Adviser Soil Research, Agricultural Research Institute, \\ Rangoon, Union of Burma \\ At present: Institute of Biological and Chemical Research on \\ Field Crops and Herbage, Wageningen, Holland
}

\begin{abstract}
SUMMARY
A considerable amount of water may be conserved for growing a second crop during the dry monsoon provided paddy fields are ploughed in a wet condition directly after the rice harvest.

The yield of cow pea as a second crop may be around $330 \mathrm{~kg}$ seed ha-1, and $4000 \mathrm{~kg}$ ha-1 of cattle fodder may be obtained if such crops as sorghum are grown.
\end{abstract}

\section{INTRODUCTION}

It is generally recognized that the living conditions of farmers in the Irrawaddi delta of Lower Burma may be improved if ways and means are found to secure at least small yields of a second crop after rice. Cultivation of second crops is an established practice in regions of sandy soils with a water table at a depth of 1-2 metres during the dry season. Owing to the lack of water, it is considered impossible to grow second crops on the basin soils which contain a large percentage of clay and where the ground water is out of reach of the roots.

A study of climatic and soil conditions and some small-scale experiments showed that at least a part of the medium-textured soils may be worked in such a way as to ensure small yields of second crops. This may be also the case in other parts of south-east Asia and on the Indian continen ${ }^{\mathrm{t}}$ where similar conditions are encountered.

\section{Cuimatic conditions}

Rainfall, free water evaporation calculated according to PeNMAN (1948) and temperature are shown in the form of a graph in Figure 1. Soon after 1st May rainfall exceeds free water evaporation and wet cultivation of the soil for rice growing is started. During the summer months rainfall exceeds $15 \mathrm{~mm}$ day $^{-1}$, whereas owing to the lack of sunshine free water evaporation is only around $3.5 \mathrm{~mm}$ day $^{-1}$. During the rice-growing about $10 \mathrm{~cm}$ of water is kept between bunds, most of the surplus water being drained off over the surface.

From November onwards free water evaporation exceeds rainfall and the fields gradually dry. The rice is harvested in November and December.

From December to April rainfall is negligible; free water evaporation increases owing to the increase in the length of the day and the height of the sun.

1) Received for publication October 14, 1958. 


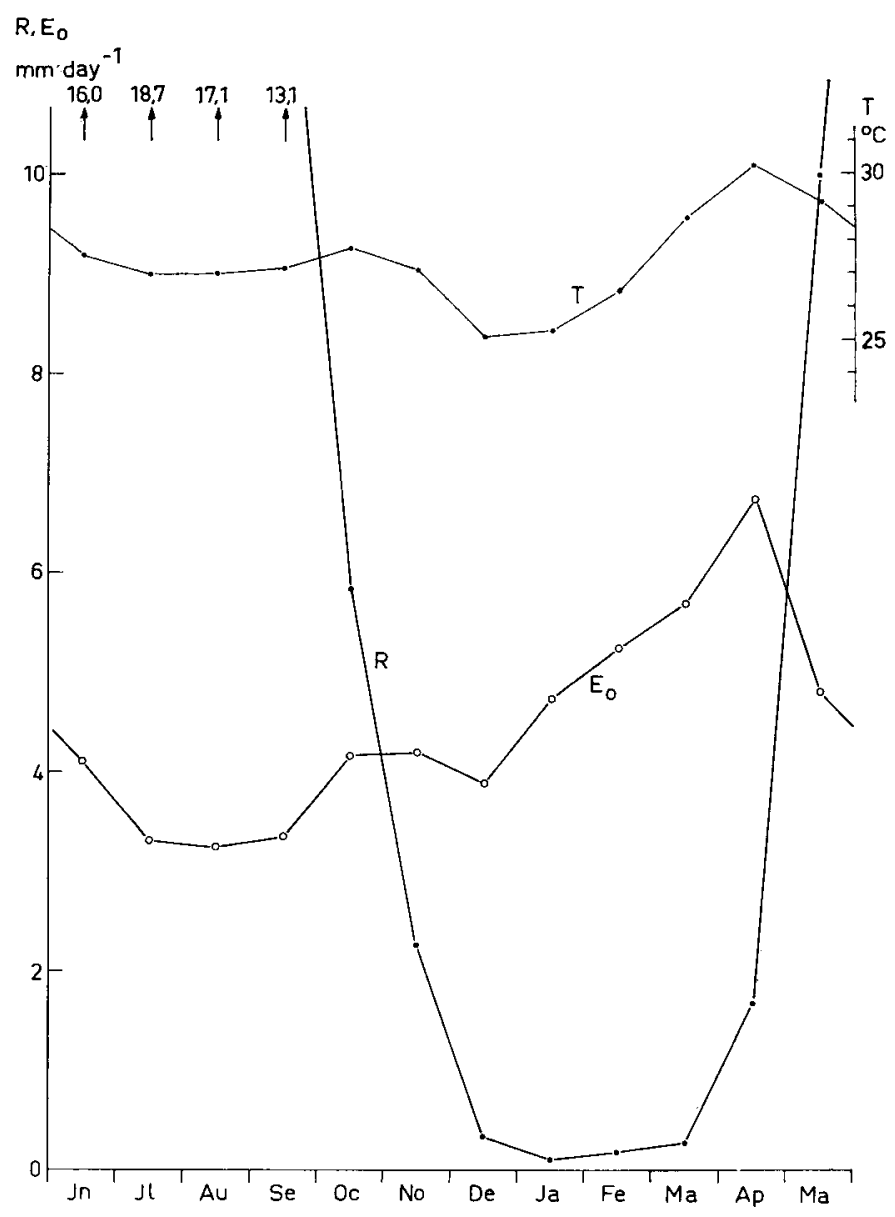

Fig. 1 Rainfall $(R)$ and Free water eVaporation $\left(E_{o}\right)$ IN MM DaY-1 aNd temperature IN ${ }^{\circ} \mathrm{C}$ throughout the year at Rangoon.

\section{SoIL CONDITIONS}

For the purpose of studying the possibilities of growing a second crop, it is convenient to divide the soils in three groups according to texture. These are :

1 Sandy soils, including sands, loamy sands and a part of the sandy loams. These soils are generally found on river ridges and on the transition area between upland and lowland. The permeability is good, so that it is only possible to cultivate paddy under conditions where subsoil drainage is low, either because of the relatively low situation or because of the presence of impermeable subsoil layers. After the paddy harvest a water table may be found around one metre below the soil surface. These soils, which occur on both sides of the Pegu Yoma, are suitable for the cultivation of groundnuts or any other second crop after paddy. Failures occur because cultivation of second crops is sometimes extended to areas where no water table is found. 


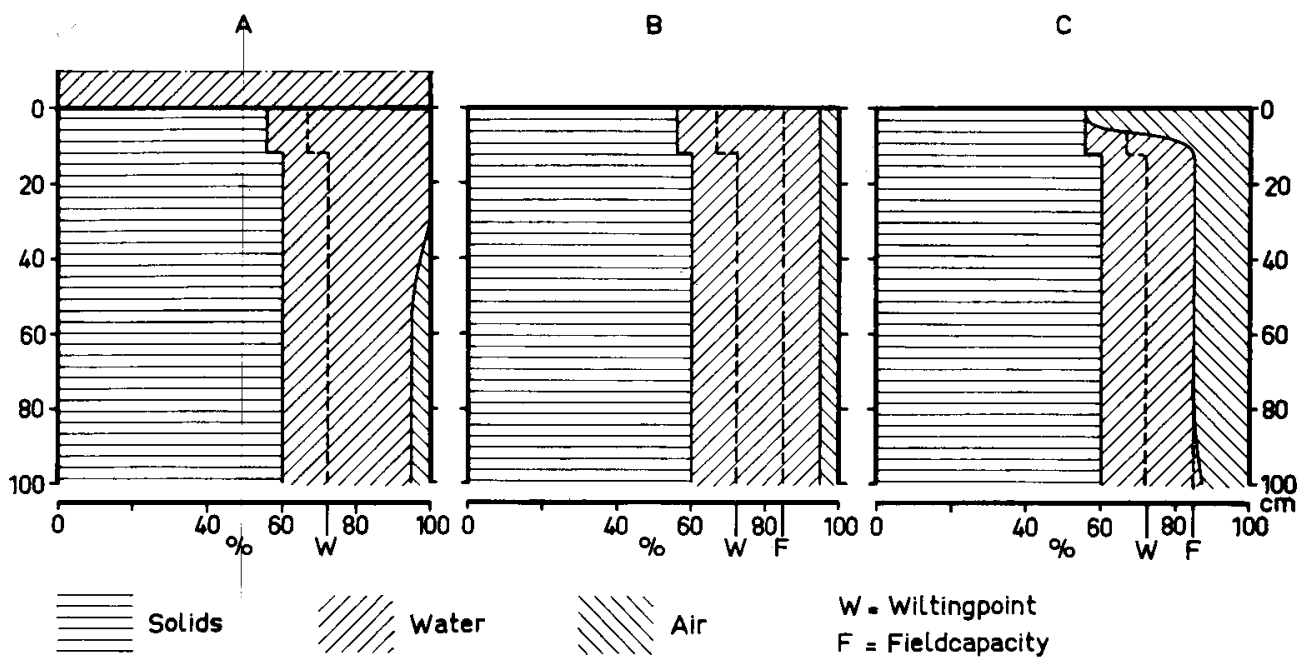

Fig. 2 Diagram showing the volume percentages of solids, Water and aIR IN The FIRST METre of a Medium-textured SOIL in the Delta of the Irrawadd.

A September, flooded paddy field.

B November, a few days after drainage of the paddy field.

C December, about six weeks after drainage of the paddy field.

2 Clayey soils, including the silty clay loams, clays and silty clays and a part of the silt loams, clay loams and sandy clays.

These typical basin soils with a slippery, wet surface in the wet season and with a surface resembling a cracked concrete floor in the dry season, are generally unsuitable for second crop growing because it is difficult to prepare a seedbed and roots are hardly able to penetrate the cracked soil. There is no sign of plant growth during the dry season.

3 Medium-textured soils, including the loams and sandy clay loams, a part of the sandy loams, and a part of the silt loams, clay loams and sandy clays.

These soils, which are scattered throughout the whole delta, do not crack and show some weed growth during the dry season. No water table is found, the soil being too impermeable to water. Second crop growing on these soils is generally considered impossible, but it has been shown that some second crops may succeed if care is taken to conserve the water present in the soil at the end of the rainy season.

Methods of water conservation, crop cultivation and the results to be expected are discussed in this paper.

The numerical data given refer mainly to a soil of this type found on the farm of the Agricultural Research Institute at Gyogon, near Rangoon (DE WIT, 1956).

\section{AIR AND WATER IN MEDIUM-TEXTURED SOILS}

The proportions of soil, water and air in the profile during September, when the soil has been covered with a water layer of about $10 \mathrm{~cm}$ for more than two months, is shown diagramatically in Figure 2 A. Except in the puddled layer, the volume of solid particles is around 60 per cent, the remaining 
40 per cent being mainly occupied by water. Subsoil drainage is extremely poor because most of the deeper soil layers are very impermeable. The wilting percentage of the soil is around 12 per cent.

Surplus water is drained off during November, a few weeks before the paddy harvest. A few days after drainage the air and water content of the profile are as shown in Figure $2 \mathrm{~B}$. The soil then contains about 35 per cent by volume of water and is still muddy and sticky.

The ripening paddy transpires water, and after the harvest water evaporates from the moist soil. The lost surface water is replaced by water from deeper layers by upward capillary flow until a moisture content of about 25 per cent by volume (about field capacity) has been reached. A dry layer is then formed on top of the soil and further evaporation is practically blocked. Air-water conditions are then as shown in Figure 2 C. During the dry season some water is lost by transpiration of a very sparse plant cover consisting of weeds.

This protective dry top layer is not formed on clayey soils. Such soils crack, so that evaporation is able to continue and the soil dries out up to a considerable depth. This is why these heavy soils are unsuitable for second crop growing if no irrigation water is supplied.

Under the condition shown in Figure $2 \mathrm{C}$, the soil can be ploughed and a seedbed prepared. Germination is often poor, however, owing to the lack of water. Where germination succeeds all plants grow reasonably well until the available water in the ploughed layer is exhausted. Subsequently most plants die within a few weeks because the roots are unable to penetrate the unploughed compact subsoil. Only a few plants growing on sites with small cracks, old root channels and so on, may obtain enough water to ripen.

It may be possible to improve the availability of water by subsoiling. This method was not tried owing to the lack of equipment. It is also known that deep ploughing may result in lower yields of the subsequent rice crop.

\section{A METHOD OF WATER CONSERvation}

The only way to obtain more water for crop growth is to cultivate the land in such a way that soon after the rice fields have been drained, the water in the soil is not evaporated and transpired, but stored until the plant is able to use it. It is therefore necessary to develop cultivation methods ensuring a dry top layer on a very wet subsoil.

For this purpose rice varieties should be grown which can be harvested in the middle of November, at the very beginning of the dry season. The yield of such varieties is only slightly below the yield of varieties harvested in December. It is then possible to keep water on the soil until about a week before the paddy harvest, subsoil drainage being almost negligible. Hence the soil-water-air contents of the profile at the time of harvest are as shown in Figure $2 \mathrm{~B}$. The amount of available water in the first $90 \mathrm{~cm}$ of the soil is then about $180 \mathrm{~mm}$, and this would be sufficient to grow crops which ripen within three months.

Several fields were ploughed under the condition indicated in figure $2 \mathrm{~B}$. After ploughing, the top of the ploughed layer dries out, but replenishment of the water from deeper layers is impossible because of the rubbish and the large pore space between the furrow slices and the wet subsoil. Directly 
after ploughing, the average moisture content of the subsoil of one of the experimental fields was 37 per cent by volume. After 2-3 months the moisture content was found to be 32 per cent by volume on a plot which had been kept free from plants. On an unploughed plot the moisture content fell to 25 per cent within four weeks and remained practically unchanged from then onwards.

A few days after ploughing the soil should be harrowed with a tine harrow in order to obtain a seedbed consisting of wet clods and dry crumbs. A great proportion of the seeds harrowed in directly afterwards germinate readily.

It was found impossible to prepare a seedbed with a disc harrow because the resultant fine top layer dries out so quickly that germination is very poor. Where soils are ploughed in a very wet condition the furrow slices collapse and the air $\mid$ spaces between the ploughed layer and the subsoil fill up and the upward capillary flow of moisture can continue despite the ploughing.

The moisture content of the ploughed layer directly after sowing was found to be 20-25 per cent by volume, around $40-45$ per cent of the volume being occupied by soil particles. On fields where the soil was ploughed up to a depth of 10 centimetres most plant species made such a poor start that the crop was a failure. Where the plough depth was more than 15 centimetres the plants developed reasonably well. It was found that about $15 \mathrm{~mm}$ of water available in the furrow slices is sufficient to cover the needs of the plants during the first weeks of growth. During this period the roots reach the ploughsole and spread out in a layer on the top of the wet subsoil in the same way as plant roots may do on the bottom of containers.

At this time the moisture content of the subsoil is still about 35 per cent by volume, of which 10 per cent is above field capacity. This 10 per cent of water moves as a result of capillary forces from a depth of about $85 \mathrm{~cm}$ towards the root layer on top of the subsoil. In this way about $70 \mathrm{~mm}$ of water gradually becomes available to the plants. During this period some small cracks often appear along which a number of roots grow downwards. In this way another $20 \mathrm{~mm}$ of water may become available to the crop, so that during the period of growth a little more than $100 \mathrm{~mm}$ of water is transpired.

At the time of harvest, about $70 \mathrm{~mm}$ of available water remains in the first $85 \mathrm{~cm}$ of the soil. This water cannot be removed by the plant because the soil is so compact that a dense root system in the subsoil is unable to develop. However, a crop like the lab bean (Dolichos lab lab) which is about four months on the field is still able to extract about $60 \mathrm{~mm}$ of water during the last month of growth.

\section{YIELDS OF SECOND CROPS}

In another paper (DE WIT, 1958) it has been shown that under arid conditions there exists a relatoinship $P=m W E_{0}{ }^{-1}$ between the dry matter production $P$ in $\mathrm{kg} \mathrm{ha}{ }^{-1}$, the transpired amount of water $W$ in $\mathrm{mm}$ and the evaporation rate of a free water surface $E_{o}$ in $\mathrm{mm} \mathrm{day}^{-1}$, provided the yield is limited by the availability of water. The value of $m$ expressed in $\mathrm{kg} \mathrm{ha}^{-1}$ day $^{-1}$ was found to be a constant which in a given climate is more or less independent of weather conditions, but depends on the plant species. The value of $m$ can be estimated from suitable experiments in containers. 
One of the most suitable second crops on the medium-textured soils in Burma is cow pea (Vigna sinensis) of the big seed variety "Bo Case Pè", which is the "New Era" variety imported from the United States. The seeds germinate well and the crop ripens within three months. The seeds are very suitable for local consumption, and the leaves of the plants may be used as a vegetable.

It has been calculated from ShaNtz and Piemiesel's (1927) transpiration ratio measurements that the value of $m$ of cow pea in the arid climate of the Midwestern United States is $100 \mathrm{~kg} \mathrm{ha}^{-1}$ day $^{-1}$.

The amount of radiation which may contribute to assimilation during the dry season in Burma is around $230 \mathrm{cal} \mathrm{cm}^{-2}$ day-1 and in the Midwestern States of the United States around $300 \mathrm{cal} \mathrm{cm}^{-2}$ day $^{-1}$, both on a clear day, so that the $m$-values in Burma are roughly 230/300 times the $m$-values in the United States (cf. DE WIT, 1958, pages 26 and 44). Consequently the value of $m$ for cow pea in Burma is around $75 \mathrm{~kg} \mathrm{ha}^{-1}$ day-1.

The amount of moisture transpired by a crop of cow pea cultivated in the manner suggested in this paper is at least $100 \mathrm{~mm} \mathrm{day}^{-1}$. As the evaporation of a free water surface in December is about $4 \mathrm{~mm}$ day $^{-1}$, the ratio $W E_{o}{ }^{-1}$ appears to be about $100 / 4=25$ days. The total dry matter production of a cow pea crop transpiring $100 \mathrm{~mm}$ of water is therefore about $25 \times 75=1900 \mathrm{~kg} \mathrm{ha}^{-1}$.

According Shantz and Piemiesel's (op.cit.) experiments the ratio between seed and total yield of cow pea is about 0.35 . The same ratio may be obtained in the field, provided the available amount of water is distributed in such a way that no damage is caused by permanent wilting during the growing period (DE WIT, 1958, page 73). The maximum calculated yield is therefore $0.35 \times 1900=670 \mathrm{~kg}$ seed ha-1.

The available water was found to be exhausted in two months on fields where the crop was sown at a row distance of 30 centimetres or less. No seeds at all were obtained on these fields. The water was much more evenly distributed throughout the growing period on fields where the row distance was 50 centimetres, but even under these conditions some of the leaves died prematurely as a result of drought. Calculated seed yields should therefore be multiplied by a reduction factor in order to allow for this damage. This reduction factor was 0.70 for durum wheat in the Midwestern States of the U.S.A. under conditions where the ratio $W E_{0}^{-1}$ was equal to 25 days (DE WIT, 1958, page 75). To be on the safe side this reduction factor for cow peas is estimated at 0.50 , so that actual yields will be around $330 \mathrm{~kg}$ seed $\mathrm{ha}^{-1}$.

The yield obtained on the farm of the Agricultural Research Institute was $280 \mathrm{~kg} \mathrm{ha}^{-1}$. The amount of moisture transpired on this field was only $90 \mathrm{~mm}$, however, because the crop rows were too wide apart. These are low yields, and where second cash crops are grown they are hardly worthwhile. However, in a region where rice and rice only is the staple, peas and beans are highly appreciated and of great dietic value.

It stands to reason that the fertility of the top soil and the structure of the profile improves on fields where leguminous plants are grown regularly as a second crop. In particular, the nitrogen fixed by these plants may result in a higher yield of the subsequent rice crop, since in the Delta of Burma 
the yield of rice is in many cases limited by the availability of nitrogen (DE WIT, 1957).

The value of $m$ for sorghum and maize in Burma is around $160 \mathrm{~kg} \mathrm{ha}^{-1}$ day $^{-1}$ (DE WIT, 1958), so that dry matter yields of $160 \times 25=4000 \mathrm{~kg} \mathrm{ha}^{-1}$ may be expected. The seeds of these plants are of little use because the Burmese farmer prefers rice which is available in sufficient amounts. These crops may be cultivated to obtain cattle fodder for the draught animals which, owing to lack of food, are in a very poor condition at the end of the dry season.

\section{ACKNOWLEDGEMENTS}

The author is indebted to Ir. P. G. DE BoER for his co-o seration and to Mr. R. C. SHAKHER for the basic radiation measurements and the calculation of the evaporation.

\section{REFERENCES}

Penman, H. L.: Natural evaporation from open water, bare soil and grass. Proc. Royal Soc. A, 193 (1948) 120-146.

Shantz, H. L. and L. N. Piemmese : The water requirements of plants at Akron, Colo. Journal of Agr. Res. 34 (1927) 1093-1190.

Wit, C. T. dE : Crop, soil and water. Stenciled report No. 12 (1956). Agr. Res. Inst., Gyogon, Burma.

- -: An analysis of some pilot fertilizer experiments on paddy. Neth. Journ. Agr. Sci. 5 (1957) 284-289.

- - : Transpiration and crop yields. Verslagen Landbouwk. Onderz. 64.6 (1958) 88 p. 